\title{
The Significance of SDGs for the Raw Materials Sector: A Stakeholders' Approach in Three ESEE Countries ${ }^{\dagger}$
}

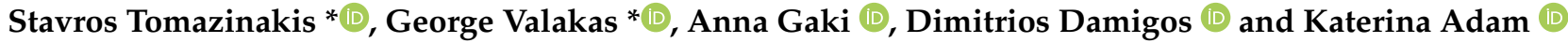 \\ School of Mining and Metallurgical Engineering, (SMME) National Technical University of Athens (NTUA), \\ Zografou Campus, 15780 Athens, Greece; gakianna@metal.ntua.gr (A.G.); damigos@metal.ntua.gr (D.D.); \\ katadam@metal.ntua.gr (K.A.) \\ * Correspondence: s.tomazinakis@gmail.com (S.T.); george.valakas@gmail.com (G.V.) \\ † Presented at International Conference on Raw Materials and Circular Economy, Athens, Greece, \\ 5-9 September 2021.
}

check for updates

Citation: Tomazinakis, S.; Valakas, G.; Gaki, A.; Damigos, D.; Adam, K. The Significance of SDGs for the Raw Materials Sector: A Stakeholders' Approach in Three ESEE Countries. Mater. Proc. 2021, 5, 48. https:// doi.org/10.3390/materproc2021005048

Academic Editor: Evangelos Tzamos

Published: 1 December 2021

Publisher's Note: MDPI stays neutral with regard to jurisdictional claims in published maps and institutional affiliations.

Copyright: (c) 2021 by the authors. Licensee MDPI, Basel, Switzerland. This article is an open access article distributed under the terms and conditions of the Creative Commons Attribution (CC BY) license (https:// creativecommons.org/licenses/by/ $4.0 /)$.

\begin{abstract}
The Raw Materials (RM) sector is linked to Sustainable Development Goals (SDGs), impacting their implementation throughout the whole RM value chain (e.g., mining, processing, metallurgy, recycling, etc.). This study aims to identify and rank the most significant SDGs for this sector, from the perspective of key stakeholders, academics, university students, professionals, and industry representatives, in three East and South-East Europe (ESEE) countries: Poland, Greece, and Slovakia. Within this framework, 423 stakeholders from the above groups provided their views in a survey with structured questionnaires. The results were analysed, based on the stakeholders' groups and the role of the sector in the countries examined. Overall, the SDGs 9-Industry, Innovation, and Infrastructure-, 8-Decent Work and Economic Growth-, and 7-Affordable and Clean Energy- were highly ranked by the stakeholders, indicating a strong link between these SDGs and the RM sector.
\end{abstract}

Keywords: stakeholders; sustainable development goals; raw materials sector; questionnaire survey

\section{Introduction}

The Raw Materials (RM) sector has a crucial role in the achievement of Sustainable Development Goals (SDGs) of the United Nations' 2030 Agenda for Sustainable Development [1], as also recognised by the European Union (EU) Member States [2,3]. In the European report of 2019, Mancini et al. [4] identified the potential impacts of the RM sector on SDGs for each main phase of the RM supply chain (Extraction, Manufacturing, Final Use, and End of Life). These impacts, positive or adverse, are largely influenced by factors such as the performance of the RM companies and the RM sector.

The three central pillars of Sustainable Development (SD), environment, economy, and society are interconnected through culture, since the national realities, capacities, and levels of development, as well as specific challenges, influence the achievement of the SDGs [5]. In this regard, key stakeholders at a national level and their perceptions, play an essential role in designing strategy and policy frameworks for the achievement of SDGs. The research on opinions and perceptions of key stakeholders of the RM sector can reveal important areas for improvement at the national performances regarding the achievement of the SDGs, since in many EU Countries the RM sector is perceived as an industry that does not make the required effort to behave responsibly towards society [6].

The successful implementation of the SD principles requires inclusive participation and effective stakeholder engagement, as recognised by the 2030 Agenda and reported in literature (e.g., [7,8]). Partnerships can lead to a more deliberate and conscious application of the SD principles [9]. Collaboration between Higher Educational Institutes (HEIs) and the industry could bridge the gap between technology, Education for SD, and pedagogy and help develop aspects of educational programs $[10,11]$. Thus, representatives from HEIs and the industry are critical stakeholders for providing and applying the SD principles in 
the RM sector. In particular, HEIs have to incorporate the SD principles in the education process for the change to be effective and embedded [12,13]. The involvement of the RM industry in this transformation is imperative, since engineering students consider the industrial experience highly valuable [14]. Considering the critical role of the above stakeholders towards the implementation of the SDGs, this study aims to identify and rank the most significant SDGs for the RM sector, from the perspective of key stakeholders in three East and South-East Europe (ESEE) countries: Poland, Greece, and Slovakia. Within this framework, 423 stakeholders from critical groups involved in the RM sector, i.e., academic staff, students-future engineers, professional engineers, and representatives from the industry, provided their views in a survey with structured questionnaires. Based on the survey data, a comparative analysis of the ranking results within the stakeholders' groups and the three ESEE countries is presented.

\section{Methodology}

\subsection{Theoretical Framework}

The European Commission has linked the 17 SDGs with specific indicators that monitor the progress towards their implementation in the EU Member States [15]. A positive contribution of the RM sector to the SDGs can be identified since Raw Material products are vital to the well-being and prosperity of societies on a larger scale [16]. As reported by Mancini and Sala [17], minerals, metals, and their industries (RM sector) create jobs and add value along the supply chains of material goods. On the other hand, adverse impacts of the RM sector on the SDGs may also exist, mostly when no effective measures are applied for environmental protection and social cohesion [17]. It is concluded thus that the whole value chain of the RM sector can have both positive and adverse impacts towards the implementation of the SDGs, depending on its performance and social responsibility. Thus, it is important to identify the relationship each SDG has with the RM sector, in order to design policies and measures to enhance their achievement.

Mancini et al. [4] studied the contribution of the RM value chain to the SDGs, by taking into account the indicators set for each goal by UN and Eurostat frameworks. The European Bank for Reconstruction and Development (EBRD) presented its own analysis [18], based on data collected from "Mapping Mining to the SDGs: An Atlas" [16]. The EBRD analysis categorised the impacts of the RM sector on SDGs as very direct, moderately direct, and indirect, having an enhancement or mitigation effect. According to EBRD, the RM sector has a very direct impact on SDGs 6-Clean Water and Sanitation-, 7-Affordable Energy-, 8-Decent Work and Economic Growth-, 9-Industry, Innovation, and Infrastructure-, 13Climate Action-, and 15-Life On Land- [18].

\subsection{Research Design and Data}

This study analyses survey data, collected within the framework of the EIT Raw Materials project "EnAct-SDGS-Enhancing the skills of ESEE RM students towards the achievement of SDGs", a two-year (2020-2021) EIT Regional Innovation Scheme (RIS).

One of the objectives of the EnAct project was to identify the current challenges faced by the RM sector and the educational needs in three ESEE countries: Greece, Poland, and Slovakia, using surveys, interviews, and communications through the EnAct-SDGs network. The research focused on three HEIs in Greece, Poland, and Slovakia and more specifically in the School of Mining and Metallurgical Engineering (SMME) of National Technical University of Athens (NTUA), the Faculty of Mining and Geoengineering of AGH University of Science and Technology, and the Faculty of Mining, Ecology, Process Control and Geotechnologies of the public Technical University of Kosice's (TUKE), respectively.

The aim of the survey was the identification of educational needs and the incorporation of suitable practices to enhance the development and adoption of Education for SD policies and strategies in the programmes of the examined universities. For that purpose, four different questionnaires were prepared in English and translated into Greek, Polish, and Slovak. The questionnaires were distributed to the key stakeholder groups: academic staff, 
students, and graduates (professionals) from each country's RM sector. The questionnaires were available online from June to September of 2020.

The present study analyses the responses of the four stakeholder groups for the question "Which of the following SDGs are most important in the RM sector?" The participants had to choose and rank the five most important goals from the list of 17 SDGs. A scale from 5 to 1 was used to indicate the range, ranking from extremely important to important, while the zero value was used to represent the SDGs, twelve of the total of seventeen, that were not selected as important by the participant.

In total 423 people participated in the online surveys, with 63 from Poland, 114 from Greece, 188 from Slovakia, and 58 from other countries. This study presents the results from the three ESEE countries: Greece, Poland, and Slovakia. The collected data from the different stakeholders were included in a single dataset and analysed. For each SD goal, the average ranking was calculated per stakeholder group. In addition, the unweighted average of four stakeholder groups was computed for each country, where the sample size of each group does not affect the overall average ranking of an SD goal. Moreover, the classification of EBRD for the type of impact that the RM sector has on the specific SDGs [18] was used for the interpretation of the results. Thus, the average ranking for each impact was computed at the country level.

To assess the effect of stakeholder groups on ranking the relevant importance of the SDGs, the non-parametric statistical test of Kruskal-Wallis was used with a significance level of $95 \%$. In the next section, the statistics of the Kruskal-Wallis test (critical value- $\mathrm{H}$, $p$-value and degree of freedom-df) are reported in the cases of significant differences between the examined groups (when $p$-value $\leq 0.05$ ).

\section{Results}

The overall ranking results regarding the significance of SDGs in the RM sector for Greece, Poland, and Slovakia are presented in Figures 1-3, respectively. The figures include the 17 SDGs sorted in declining order of significance, based on the unweighted average of four stakeholder groups for each country. The results indicate that SDGs 9-Industry, Innovation, and Infrastructure-, 8-Decent Work and Economic Growth-, and 7-Affordable and Clean Energy-, were ranked among the five most important goals for the RM sector, by all countries.

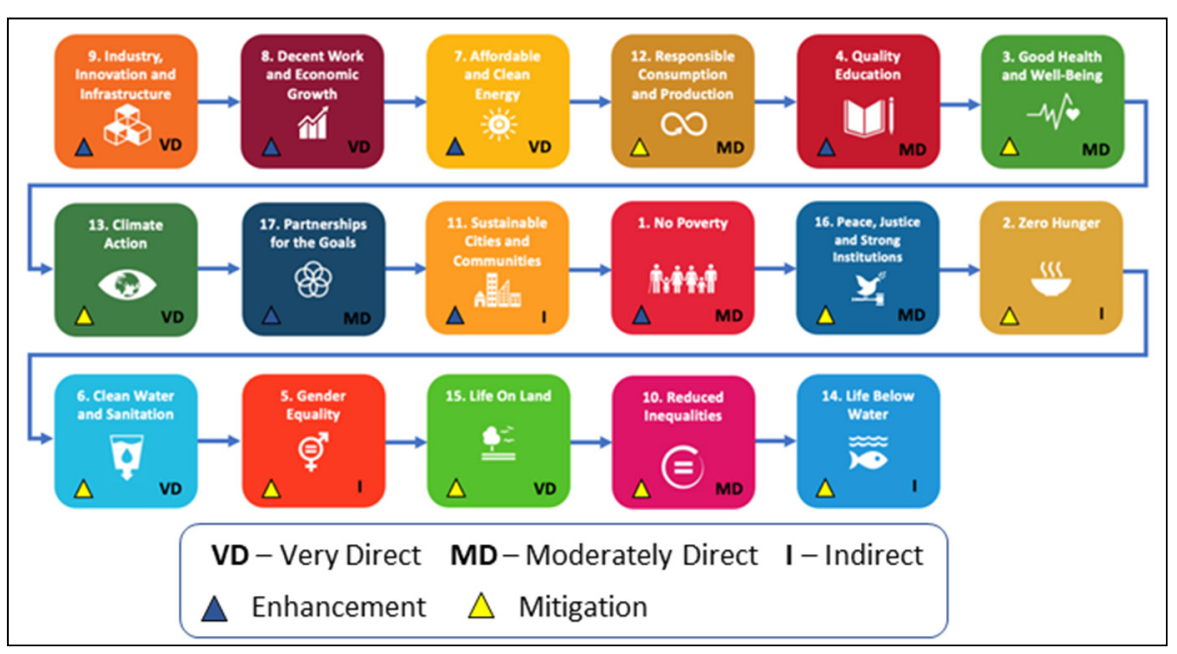

Figure 1. Ranking of the significance of SDGs for the RM sector by the Greek stakeholder groups. The type of RM sector impact on the specific SDGs was codified based on EBRD [18]. 


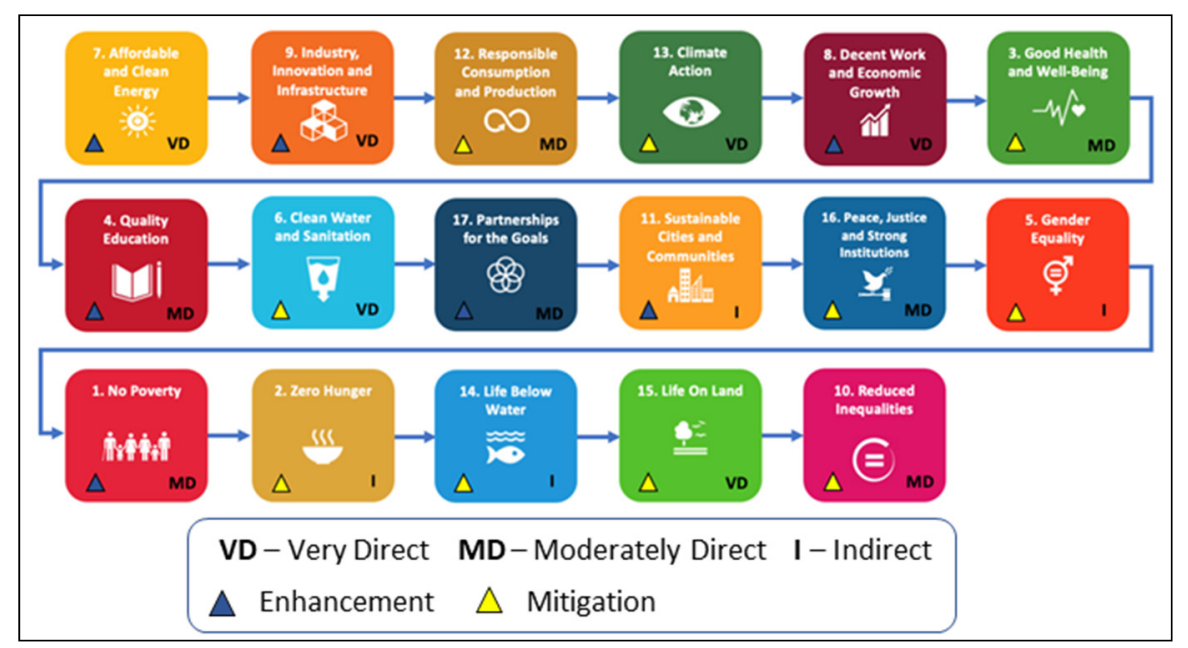

Figure 2. Ranking of the significance of SDGs for the RM sector by the Polish stakeholder groups. The type of RM sector impact on the specific SDGs was codified based on EBRD [18].

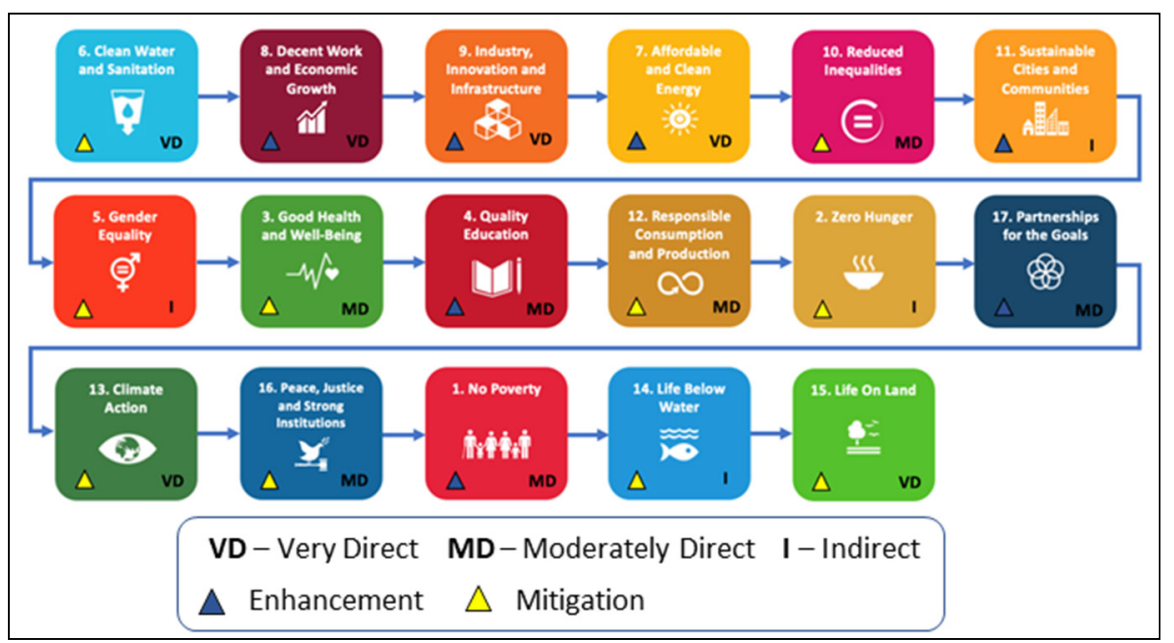

Figure 3. Ranking of the significance of SDGs for the RM sector by the Slovak stakeholder groups. The type of RM sector impact on the specific SDGs was codified based on EBRD [18].

The Greek stakeholders ranked SDGs 9-Industry, Innovation, and Infrastructure-, 8-Decent Work and Economic Growth-, 7-Affordable and Clean Energy-, 12-Responsible Consumption and Production-, and 4-Quality Education- as the most important goals related to RM sector, with the overall results been presented in Figure 1. In this figure, the type of impact that the RM sector has on the specific SDGs codified in the EBRD analysis [18] is also noted. Differences were observed between the stakeholders' views for the relative significance of 3 of the 17 SDGs, according to the results of the KruskalWallis H test. Academic staff assessed SDG 6 -Clean Water and Sanitation- with higher importance than the other three groups $(\mathrm{H}=10.580, p=0.014, \mathrm{df}=3)$. Students evaluated the importance of SDG 7 -Affordable and Clean Energy- with a lower rank than the other three groups $(\mathrm{H}=11.239, p=0.011, \mathrm{df}=3)$. Moreover, SDG 12 -Responsible Consumption and Production- was ranked more highly by the professionals and the representatives of the industry than the other groups $(\mathrm{H}=10.410, p=0.015, \mathrm{df}=3)$.

The ranking of the 5 most significant SDGs from the perspective of Polish stakeholders is the following: 7-Affordable and Clean Energy-, 9-Industry, Innovation, and Infrastructure-, 12-Responsible Consumption and Production-, 13-Climate Action-, and 8-Decent Work and Economic Growth-, as seen in Figure 2. Statistically, SDGs 7-Affordable and Clean Energy- and 12-Responsible Consumption and Production- presented significant differences between the four stakeholder groups, with SDG 7 ranked higher from the 
professionals and the industry $(\mathrm{H}=17.865, p=0.000, \mathrm{df}=3)$ and SDG 12 assessed with higher importance from the industry than the other three groups $(H=10.373, p=0.016$, $\mathrm{df}=3$ ).

According to the Slovak stakeholders, the 5 most significant SDGs for the RM sector are 6-Clean Water and Sanitation-, 8-Decent Work and Economic Growth-, 9-Industry, Innovation, and Infrastructure-, 7-Affordable and Clean Energy-, and 10-Reduce Inequalities-, with the full results been presented in Figure 3. Only students ranked the importance of SDG 4 -Quality Education- higher than the other groups $(\mathrm{H}=11.001, p=0.003, \mathrm{df}=3)$, and no other statistical differences were observed.

As opposed to the few differences observed among the stakeholder groups in each country, heterogeneity was recorded between the responses on country level. SDGs 7Affordable and Clean Energy- and 13-Climate Action- were evaluated more highly by Polish stakeholders than the Greek and Slovak ones $(\mathrm{H}=9.431, p=0.009, \mathrm{df}=2$ and $\mathrm{H}=30.014, p=0.000, \mathrm{df}=2)$. The SDGs 9-Industry, Innovation, and Infrastructureand 12-Responsible Consumption and Production- were ranked more highly by Greek and Polish stakeholders $(\mathrm{H}=20.056, p=0.000, \mathrm{df}=2$ and $\mathrm{H}=32.530, p=0.000, \mathrm{df}=2$, respectively). SDGs 5-Gender Equality- and 6-Clean Water and Sanitation-, were ranked more highly by Slovak participants, quite highly by the Polish participants, and less highly by the Greek participants $(\mathrm{H}=32.777, p=0.000, \mathrm{df}=2$ and $\mathrm{H}=38.518, p=0.000$, $\mathrm{df}=2$, respectively). Moreover, Slovak stakeholders assessed the SDGs 10 -Reduced Inequalities- and 11-Sustainable Cities and Communities- with higher importance than the other stakeholders of the examined countries $(\mathrm{H}=50.002, p=0.000, \mathrm{df}=2$ and $\mathrm{H}=6.326 .518$, $p=0.042, \mathrm{df}=2$, respectively).

Based on the stakeholders' views for the three ESEE countries examined, the average of the ranking of the SDGs based on the type of impact that the RM has on these SDGs, regarding its directness, indirect, moderately direct, very direct, and their enhancement or mitigation is presented in Figure 4. The stakeholders from the three countries selected with a higher frequency as more significant, the SDGs that are directly and positively impacted by the RM sector activities. Figure 4 also shows that there are significant differences in the rankings at country level. For example, Greek and Polish stakeholders ranked SDGs that the RM sector has a moderately direct impact on, higher than SDGs being indirectly impacted by the sector. In contrast, Slovak stakeholders ranked the SDGs being moderately directly and indirectly impacted by the RM sector, in a similar way.

(a)

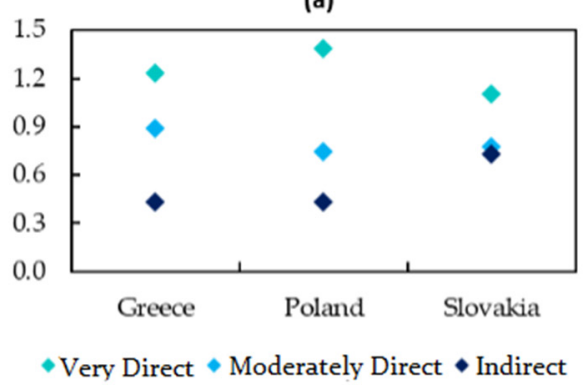

Type of Impact

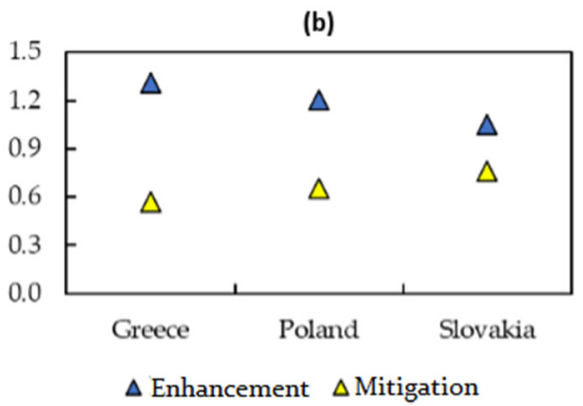

Figure 4. Summary of the stakeholders survey results regarding the average significance of SDGs in the RM sector for the three ESEE countries examined, as per the type of impact: (a) Very Direct, Moderately Direct, Indirect, and (b) Enhancement and Mitigation, EBRD [18].

\section{Discussion-Conclusions}

The RM sector has an essential contribution to national and regional economies of Greece, Poland, and Slovakia. Greece and Poland are countries with long mining traditions, increased Raw Materials business potential, and leading international mining companies, while Slovakia has a low to medium mining business potential and the mining sector has 
a lower endowment to its economy than Greece and Poland [18]. Based on International Council of Mining and Metals data of 2018, the contribution of the mining sector to the Gross Domestic Product (GDP) (value of metallic mineral and coal production, as percentage of GDP) of Greece, Poland, and Slovakia was $1.03 \%, 2.02 \%$, and $0.02 \%$, respectively [19]. In 2018, the Polish mining and quarrying sector employed 144,900 employees or $0.91 \%$ of the country's workforce. The respective number for Greece was 7703 and for Slovakia 6777 or $0.21 \%$ and $0.27 \%$ of the country's workforce, respectively $[20,21]$.

The overall SDG Index Score, measuring the progress towards achieving all 17 SDGs for Greece, Poland, and Slovakia in 2020 was 62.0, 69.6, and 68.8, respectively, on a scale from 50 to 90 [22]. None of the three ESEE countries has so far achieved the SDG their RM stakeholders considered the most important for the sector. According to the "2020 Europe Sustainable Development Report" [22], major challenges remain for the implementation of SDG 9-Industry, Innovation, and Infrastructure- in Greece. In Poland, the challenges remaining for the implementation of SDG 7-Affordable and Clean Energy- are significant, and lastly Slovakia is the country closer to the achievement of its top ranked goal, SDG 6 -Clean Water and Sanitation-, with only some challenges remaining [22].

For the achievement of SD in the RM sector, a strategy involving HEIs together with the industry is very valuable. The diffusion of SD principles from academic staff to students, the adoption of those principles from students, the knowledge and awareness of professional engineers, and the application of SD practices by the industries constitute the main system for the successful implementation of SDGs in the RM sector [12,13].

Having examined the results of the survey, it is concluded that there are significant differences between the stakeholders on the country level in the ranking of the relative importance that the specific SDGs have for the RM sector. However, a few differences in the ranking of the SDGs are observed among the stakeholder groups in each country. Furthermore, the ranking of SDGs, as documented by the views of the stakeholders, depends more on the type of impact the RM sector has on these SDGs. The participants from the three ESEE countries examined, ranked highly the three SDGs, 7-Affordable and Clean Energy-, 8-Decent Work and Economic Growth-, and 9-Industry, Innovation, and Infrastructure-, which are directly and positively impacted by the activities of the sector. Subsequently, the results of the present survey will be taken into account in the Action Plan developed within the EnAct-SDGs programme, which will act as a driver to modernise the RM education practices, ensuring the incorporation of the SD principles in the educational programmes of the ESEE universities, strengthening skills, and increasing the capacity of university graduates and RM professionals.

Funding: Research data presented in this article were obtained within the EnAct SDGs project, No. 19258 funded by EIT RawMaterials, which is gratefully acknowledged.

Institutional Review Board Statement: Not applicable.

Informed Consent Statement: The study was conducted according to the General Data Protection Regulation (Regulation No. 2016/679). Ethical review and approval were waived for this study, due to the data being collected through an anonymous online questionnaire and no sensitive personal data being requested.

Data Availability Statement: No publicly available data.

Acknowledgments: The authors would like to thank the colleagues from AGH University of Science and Technology, Technical University of Kosice's-TUKE and the other partners of EnAct project, such as the Montan Universität Leoben-MUL, Technische Universität Bergakademie Freiberg-TUBAF, Uni Trento, Hub Innovazione Trentino S.c.a.r.l.-HIT, and the industrial partner, MYTILINEOS, for their contribution to preparing and disseminating the survey.

Conflicts of Interest: The authors declare no conflict of interest. 


\section{References}

1. United Nations. The 2030 Agenda for Sustainable Development and the SDGs. 2015. Available online: https://sdgs.un.org/2030 agenda (accessed on 8 August 2021).

2. European Commission. Making Raw Materials Available for Europe's Future Wellbeing. In Proposal for a European Innovation Partnership on Raw Materials; Publications Office of the European Union: Brussels, Belgium, 2012.

3. European Commission. The New European Consensus on Development 'Our World, Our Dignity, Our Future'. Joint Statement by the Council and the Representatives of the Governments of the Member States Meeting within the Council, the European Parliament and the European Commission; Publications Office of the European Union: Luxembourg, 2018.

4. Mancini, L.; Vidal-Legaz, B.; Vizzarri, M.; Wittmer, D.; Grassi, G.; Pennington, D. Mapping the Role of Raw Materials in Sustainable Development Goals. In A Preliminary Analysis of Links, Monitoring Indicators, and Related Policy Initiatives; EUR 29595 EN; Publications Office of the European Union: Luxembourg, 2019; ISBN 978-92-76-08385-6.

5. UNESCO. United Nations Decade of Education for Sustainable Development 2005-2014. In Proceedings of the International Implementation Scheme, Draft, January 2005; UNESCO: Paris, France, 2005. Available online: http:/ /unesdoc.unesco.org/images/ 0013/001399/139937e.pdf (accessed on 8 August 2021).

6. European Commission. EIP on Raw Materials. In Raw Materials Scoreboard; Publications Office of the European Union: Luxembourg, 2016.

7. Gray, B.; Purdy, J. Collaborating for Our Future: Multistakeholder Partnerships for Solving Complex Problems; Oxford University Press: Oxford, UK, 2018.

8. Senge, P.; Smith, B.; Kruschwitz, N.; Laur, J.; Schley, S. The Necessary Revolution: How Individuals and Organsiations Are Working Together to Create a Sustainable World; Nicholas Brealey Publishing: London, UK, 2008.

9. UNESCO. Issues and Trends in Education for Sustainable Development; Leicht, A., Heiss, J., Byun, W.J., Eds.; United Nations Educational, Scientific and Cultural Organization: Paris, France, 2018; ISBN 978-92-3-100053-9. Available online: https:/ / unesdoc. unesco.org/ark:/48223/pf0000261445 (accessed on 8 August 2021).

10. Joyce, A. Massive Open Online Courses for Education for Sustainable Development. 2017. Available online: https://alexajoyce. wordpress.com/author/ajoyce (accessed on 8 August 2021).

11. Lamb, F.; Arlett, C.; Dales, R.; Ditchfield, R.; Parkin, B.; Wakeham, W. Engineering Graduates for Industry; Royal Academy of Engineering: London, UK, 2010.

12. De Graaff, E.; Kolmos, A. Management of Change-Implementation of Problem-Based and Project-Based Learning in Engineering; Sense Publishers: Rotterdam, The Netherlands, 2007.

13. Trowler, P.; Saunders, M.; Knight, P. Change Thinking, Change Practices-a Guide to Change for Heads of Department, Programme leaders and Other Change Agents in Higher Education; LTSN Generic Centre: York, UK, 2003.

14. Collins, K.; Davies, J. Feedback through student essay competitions: What makes a good engineering lecturer? Eng. Educ. J. High. Educ. Acad. Eng. Subj. Cent. 2009, 4, 8-15. [CrossRef]

15. Eurostat. Sustainable Development in the European Union. In Monitoring Report on Progress towards the SDGs in an EU Context; Publications Office of the European Union: Luxembourg, 2020.

16. Columbia Center on Sustainable Investment (CCSI); UNDP; UN Sustainable Development Solutions Network (SDSN); World Economic Forum. Mapping Mining to the Sustainable Development Goals: An Atlas. Sustainable Development Solutions Network. 2016. Available online: www.jstor.org/stable/resrep15880 (accessed on 24 June 2021).

17. Mancini, L.; Sala, S. Social impact assessment in the mining sector: Review and comparison of indicators frameworks. Resour. Policy 2018, 57, 98-111. [CrossRef]

18. EBRD. Extractive Mining Industries Strategy 2018-2022; As Approved by the Board of Directors on 13 December 2017; EBRD: London, UK, 2017.

19. ICMM. Role of Mining in National Economies: Mining Contribution Index, 5th ed.; ICMM: London, UK, 2020. Available online: https: //www.icmm.com/website/publications/pdfs/social-performance/2020/research_mci-5.pdf (accessed on 8 August 2021).

20. Eurostat Data. Annual Detailed Enterprise Statistics for Industry (NACE Rev.2, B-E). Available online: https: / / ec.europa.eu / eurostat/databrowser/view/SBS_NA_IND_R2_custom_1188157/default/table?lang=en (accessed on 8 August 2021).

21. Eurostat Data. Employment and Activity by Sex and Age-Annual Data. Available online: https://ec.europa.eu/eurostat/ databrowser/view/LFSI_EMP_A_custom_1188091/default/table?lang=en (accessed on 8 August 2021).

22. SDSN; IEEP. The 2020 Europe Sustainable Development Report: Meeting the Sustainable Development Goals in the Face of the COVID-19 Pandemic; Sustainable Development Solutions Network and Institute for European Environmental Policy: Paris, France; Brussels, Belgium, 2020. 